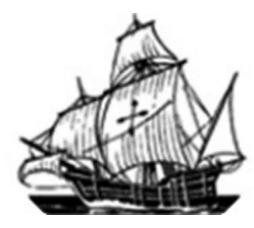

\title{
Aconteceu em Guaporé: as performances de
}

\section{meu pai}

\author{
Karen Cristina Bonatto ${ }^{1}$ (UFRGS/CNPq)
}

\begin{abstract}
Resumo: Este trabalho constitui uma reflexão sobre as narrativas orais tendo em vista os processos envolvidos em sua produção e recepção a partir de um vídeo de meu pai contando histórias. As práticas da voz permitem descobrir as raízes culturais de um grupo social. Parto da ideia de performance de Paul Zumthor (1997), que define a poesia como uma ação complexa pela qual uma mensagem poética é simultaneamente transmitida e percebida. Com a consolidação da escrita pelos meios impressos e mais recentemente com a valorização da imagem e dos inúmeros recursos midiáticos, ela foi perdendo a força, ainda mais quando se trata do dizer poético. Victor Vich e Virginia Zavalla (2004) trazem a ideia do testemunho, que transmite o mais característico do ser humano: a experiência e sua representação, o viver e o falar. Mas não é possível narrar todas as experiências, tudo o que se viveu. O testemunho seria, então, o que é dito dentro dos limites do possível e do impossível. O narrador escolhe o que vai contar e de que forma irá contar, analisa os fatos vividos ou vistos e os relaciona com sua identidade, tornando-se autor do que foi contado, mas também de uma memória compartilhada.
\end{abstract}

Palavras-chave: performance; narrativas orais; memória; oralidade.

Résumé : Ce texte constitue une réflexion sur les narratives orales étant donné les processus impliqués dans sa production et réception à partir d'n vidéo de mon père dont il raconte ses histoires. Les practiques de la voix permettent découvrir les sources culturelles d'un groupe sociaux.. Je m'appui dans le concept de performance de Paul Zumthor (1997) qui la défine autant qu'une action complexe par laquelle une message poétique est au même temps transmis et possible d'être perçu. Avec la consolidation de l'écriture pour les médias imprimés et plus recemment avec la valorisation de l'image et des divers réseaux médiatiques, la voix a perdu, peu à peu, sa force, surtout en rélation avec le dire poétique. Victor Vich et Virginia Zavalla (2004) nous portent l'idée du témoignage qui transmet le plus caracteristique du être humain: l'éxperience et sa répresentation, le vivre et le parler. Mais c'est pas possible raconter toutes les éxperiences, tout ce qu'on a vécu et le témoignage serait, alors, ce qui est dit aux limites du possible et de l'impossible. Le narrateur choisit ce qu'il va raconter et la façon qui utilsera pour le faire, il analyse les faits experimentés ou qu'on été vus en les rapportant avec sa identité et il devient auteur de ce qu'il a raconté, mais aussi de sa mémoire partagée.

Mots-clés : performance; narratives orales; mémoire; oralité.

1 Mestranda em Literaturas Portuguesa e Luso-Africanas pela Universidade Federal do Rio Grande do Sul. Bolsista do Conselho Nacional de Desenvolvimento Científico e Tecnológico (CNPq). E-mail: kbonatto@gmail.com 
Meu interesse pelas poéticas da voz surgiu quando cursei a disciplina "Literatura Oral Tradicional”, com a professora Ana Lúcia Liberato Tettamanzy na UFRGS. Depois de ler vários teóricos que tratam sobre o assunto, fomos instruídos a fazer um trabalho de campo: deveríamos escolher uma pessoa e ouvir suas histórias, gravando essas narrações e apresentando-as em aula. Meu pai foi minha escolha direta, já que sempre amei ouvir suas histórias; foi uma oportunidade de aliar a prazerosa escuta de alguém próximo a mim com a experiência no mundo acadêmico, transformando o meu olhar a respeito de meu pai e suas histórias. O vídeo gravado faz parte do DVD Narradores Orais 2009, do Projeto "A vida reinventada: pressupostos teóricos para análise e criação de acervo de narrativas orais", e se encontra no acervo digital da Biblioteca Setorial de Ciências Sociais e Humanas da UFRGS.

A palavra, aqui no âmbito da voz, já foi a lei, já foi motivo de honra para o homem, já foi a base da sociedade. Com a invenção da escrita, ela foi perdendo a força. Ainda mais quando trata-se do dizer poético, a voz foi cedendo espaço para a letra. Com o avanço tecnológico, então, a apreciação do poético foi sendo feita por inúmeros recursos midiáticos, focando para o novo, para o moderno, tomando o espaço do homem, que quase não tem mais tempo para parar e ouvir o que outro tem a contar. As relações interpessoais tornaramse, a meu ver, mecânicas demais; e esse contato com o outro é o que há de mais puro, de mais sublime nas manifestações orais.

Adolfo Colombres (1997) acredita que estamos passando por um novo processo de colonização cultural, e que podemos estar caindo em uma verdadeira mutação antropológica, onde o homem inquieto, que deseja explorar as profundezas do pensamento e dos sentimentos está dando lugar a um homem conformista, sem solidariedade. É preciso, então, refletir sobre o caminho que se 
está trilhando e dar "mais espaço" às relações humanas, ouvir a experiência do outro, que reconstrói, ao mesmo tempo, sua identidade e a tradição cultural de determinado lugar, pois sem memórias e recordações, tanto o indivíduo quanto os sujeitos coletivos ficariam aniquilados. Recuperar a memória, então, é recuperar a consciência de si. (COLOMBRES, 1997)

Não se pode negar que existe, ainda, um preconceito, dentro da academia, voltado àqueles que fazem da voz, ao invés da escrita, seu instrumento de transmissão da literatura. O cânone, a tradição letrada e seu preconceito com as demais formas de literatura acabam distanciando ainda mais a letra e a voz: "A tentativa de retomar essas vozes pelo estudo dos próprios sujeitos que as produzem não ficou livre de uma resistência por parte dos pesquisadores mais convencionais dos estudos literários" (LEITE \& FERNANDES, 2007, p XII).

Há espaço, sim, para a sensibilidade dentro da academia, e mais do que espaço, há necessidade. Como sujeitos, não somos apenas seres racionais, somos seres emocionais também, e é isso o que nos torna humanos. Esse contato com o outro só é possível nas manifestações orais, é preciso, então, valorizar essas manifestações, ter em mente que a experiência do outro nos enriquece.

Desde o desenvolvimento da Psicanálise por Freud, em certas correntes do pensamento ocidental contemporâneo, o homem não é mais percebido (e definido) como sujeito apenas racional, mas sim como constituído também de desejo, em certa medida inconsciente. Todos os atos humanos, sobretudo simbólicos, são, portanto, perpassados pelo desejo, assim como também pelas circunstâncias. Descarta-se, então, 'a possibilidade de um relacionamento puramente objetivo, ou puramente subjetivo, entre o homem e a realidade, sujeito e objeto, leitor e texto'. (ALMEIDA, QUEIROZ, 2004, pg. 166)

Acredito que o que Walter Benjamin (1997) escreveu é fundamental para entendermos as narrativas orais: só quem tem experiências tem o que narrar. E a experiência é indiscutivelmente única para cada um, se dois indivíduos viverem uma mesma situação, com certeza a experiência obtida por eles será diferente. Jorge Larrosa Bondía afirma que "a experiência é o que nos passa, o que nos 
acontece, o que nos toca. Não o que se passa, não o que acontece, ou o que toca. A cada dia se passam muitas coisas, porém, ao mesmo tempo, quase nada nos acontece.” (BONDÍA, 2002, p. 21)

É a experiência de que a arte de narrar está em vias de extinção. São cada vez mais raras as pessoas que sabem narrar devidamente. Quando se pede num grupo que alguém narre alguma coisa, o embaraço se generaliza. É como se estivéssemos privados de uma faculdade que nos parecia segura e inalienável: a faculdade de intercambiar experiências. (BENJAMIN, 1987, p. 197)

Como bem observou Benjamin, existe uma grande carência de trocar experiências. Nunca se passaram tantas coisas no mundo, porém a experiência está cada vez mais rara. Um dos motivos disso acontecer é o excesso de informação, e informação não é experiência. Ela é quase o contrário da experiência, quase uma “antiexperiência” (BONDÍA, 2002).

Tudo o que foi contado neste vídeo faz parte da experiência de vida do meu pai, faz parte de sua vida, se outra pessoa que estava com ele na sala de cinema para assistir a "Os canhões de Navarone" contasse essa história, ela com certeza seria diferente. Ouviríamos o que foi importante a este contador, que experiências adquiriu com esse episódio, pois é justamente através das performances e narrativas que as experiências ganham forma e significado. Outra teórica que discute sobre a questão da experiência, é a antropóloga Luciana Hartmann:

[...] o trabalho com narrativas está sempre, e inevitavelmente, relacionado à problemática da experiência. Segundo essa perspectiva uma das principais maneiras que o ser humano teria de manifestar, comunicar e até mesmo compreender a experiência seria colocá-la sob a forma narrativa. (HARTMANN, 2005, p. 126)

"A performance é a ação complexa pela qual uma mensagem poética é simultaneamente, aqui e agora, transmitida e percebida" (Zumthor 1997). Ela é 
capaz de fazer e transformar; e reúne, em um mesmo acontecimento, comunicação, transmissão, ensinamento, aprendizado e rememoração.

A performance é intrínseca ao uso do corpo, sendo então um acontecimento oral e gestual. O corpo se envolve com o que é dito e a cada momento se transforma, expressa a emoção, o ritmo de quem conta. E isso é indiscutivelmente único a cada indivíduo, o contador se compromete com sua audiência, mostrando as sensações do seu mundo particular para os demais. Todo o corpo de meu pai 'fala' quando narra, no corpo se materializa aquilo que é próprio, que é único do narrador. O rosto, ao lembrar do antigo amigo, expressa emoção e carinho, suas risadas, seus gestos e movimentos dão vida à história. Quando ele conta que a pantera vai juntar a pedra, por exemplo, ele interpreta, espicha seu braço e ameaça jogá-la. Isso é seu corpo emanando a narração.

[...] nas performances narrativas o tempo e o espaço do contador encontram- se com o tempo e o espaço da audiência, propiciando uma interação, um diálogo e uma troca de experiências que estão, neste "aqui e agora" compartilhado, mostrando a própria cultura em emergência. (HARTMANN, 2005)

Originalmente, a performance é um ato de comunicação em que a produção é simultânea à recepção, e assim como a audiência reage ao que ouve do narrador, este também reage a sua plateia, o que permite a interação entre eles. Precisamos levar em conta, ainda, que ela sempre está inserida em um determinado contexto social e é constituída por múltiplos determinantes: os discursos orais se constituem pelo modo que se produzem, pelas circunstâncias em que se encontram, pelo público a que se dirigem e pela imagem que contém. A oralidade é um evento, uma performance, e para estudá-la devemos ter sempre em mente que ela faz referência a um tipo de interação social; é uma prática, uma experiência que se realiza e um evento do qual participamos (VICH \& ZAVALLA, 2004). 
Doralice Alcoforado reforça a ideia de que o discurso poético oral não se resume, então, a um contexto exclusivamente verbal. "Aspectos translinguistícos, específicos do discurso oral, associam-se à voz para the dar mais concretude, como os gestos, a dicção entonacional, as pausas, a mímica facial, os movimentos do corpo, até mesmo o estímulo da platéia, que não reduzem a oralidade à ação exclusiva da voz" (ALCOFORADO, 2007, p 4). Sendo assim, as manifestações da voz são peculiares e marcantes, e a cada momento de produção temos uma nova performance e uma nova sensação.

Existem várias formas de registrar essas performances, o registro audiovisual é o mais completo, é o que permite uma maior observação da performance, possibilitando a circulação da mesma. Porém, em qualquer forma de registro, muito se perde do ato performático.

Como bem pontuam ALMEIDA e QUEIROZ (2004), os estudos das manifestações orais da literatura debruçam-se sobre dois objetos: a performance (com todos os seus componentes) e sua representação através de suportes gerados pela indústria (a gravação em fita magnética, o vídeo, o livro), que recolocam as questões de linguagem, a partir de cada processo de representação.

\begin{abstract}
Assim, podemos dizer que, ao lidarmos com gravações em fitas sonoras, por exemplo, enfretamos o problema da perda da imagem como elemento integrante da performance; a gravação em vídeo, por outro lado, embora preserve a imagem, tem de lidar com a redução de cenas, uma vez que, por exigência do próprio meio, o tempo de projeção terá de ser muito menor do que o tempo da apresentação oral; o registro em livro, por sua vez, dando-se necessariamente em linguagem verbal escrita (ainda que não se limitando a ela), configura-se, em princípio, como aquele em que se verifica mais perda, pois nele se perde a própria essência da literatura oral - a voz. ( p. 164)
\end{abstract}

As gravações com meu pai foram feitas na nossa casa, em nossa sala de estar; estávamos apenas meu pai e eu, deixei a câmera posicionada e começamos nossa conversa. Em alguns momentos ouvimos vozes e barulhos, resultado de uma casa cheia como a nossa. No início, a câmera causou um certo estranhamento a ele, mas, aos poucos, foi ficando mais a vontade, deixando que 
a presença da filmadora não o perturbasse. Estava sentado no sofá e foi se mexendo mais, colocando os pés para cima, ficando mais confortável.

Algumas das histórias têm um lado bastante cômico, apresentam situações bastante inusitadas. Outras, um lado bastante sério, histórias sobrenaturais que aconteceram com meu pai e que ele nunca soube explicar. A história da pantera cor de rosa, por exemplo, entra no time das histórias engraçadas, e aconteceu com um conhecido do meu pai. Ele não quer citar o nome, pois o sujeito era gente boa, "colono forte" nas suas palavras, e pode ter algum parente que assista ao vídeo e não goste. Depois de eu dizer que não tem problema mencionar o nome, ele acaba revelando: Seu Tauffer. Essa situação só aconteceu por causa da presença da câmera, quando o pai contava essa história, nunca teve problemas em identificar a pessoa; a câmera, muitas vezes, faz o contador pensar nas consequências de suas histórias, causando um certo receio. Da mesma forma, o ouvinte, que depois transpõe a performance para outros meios, também manifesta a preocupação com a fidelidade possível nesse processo, que pode ser entendido como uma tradução:

\begin{abstract}
Transcrever é traduzir; como na tradução, na transcrição também não há um "texto original" - que seria, para os defensores da fidelidade, o texto oral da performance. $\mathrm{O}$ coletador, responsável pela transcrição, portanto, pela escrita do conto oral, inscreverá ali também, nas páginas do livro, sua leitura, sua assinatura, sua letra. Sua escuta será sempre seletiva; processará escolhas - algumas ditadas pelo método científico, outras pela estética da época da publicação, outras ainda por afetos, sonoridades que acalantam memórias inconscientes do escriba-escritor.(idem, p.167)
\end{abstract}

Meu pai conta as mais diversas histórias sobre os costumes e o desenvolvimento de sua cidade, Guaporé, assim como a reação dos que viviam lá naquela época frente aos novos acontecimentos. Ficamos sabendo de algumas tradições e costumes da cidade. Contar/recriar a tradição é uma das característica das narrativas orais, porém, é preciso deixar claro que meu pai coloca-se como sujeito e autor das histórias, construindo a tradição sob o seu ponto de vista. 
Quando narramos alguma história, não importa se a vivemos, a vimos ou apenas dela ouvimos falar, o fato é que nos apropriamos dela. Colocamos nossas marcas de sujeito e autor. É o que explica Frederico Fernandes (2007):

O narrador, ao atualizar o arquétipo, desempenha uma tripla função na cultura oral: narra, é o performer sensível ao auditório, já que incorpora a voz da comunidade; ouve, troca experiências com outros narradores e absorve as histórias que lhe contam; e cria, torna-se responsável por constituir um sentido para o que ouviu, bem como por atualizar com significantes e significados diferenciados. (p.56)

A autoria está presente em todos os momentos, desde as palavras que escolho para contar, até os fatos que decido ocultar ou evidenciar. Zumthor (2007) já nos disse que a palavra não é inocente, no momento que escolho o que vou contar e como, estou me marcando como sujeito desse discurso: "Na tradição oral, haverá tantas variantes menores de um mito quanto forem as repetições dele, e a quantidade de repetições pode aumentar indefinidamente.”

As características orais, evidentemente, não carecem de originalidade própria. A originalidade narrativa reside não na construção de novas histórias, mas na administração de uma interação especial com sua audiência, em sua época - a cada narração, deve-se dar à história, de uma maneira única, uma situação singular, pois nas culturas orais o público deve ser levado a reagir, muitas vezes intensamente. (ONG, 1998, p. 53)

Quando meu pai conta a história da pantera, por exemplo, ele imprime suas marcas nela, supõe coisas, como por exemplo, que a televisão devia ser de 110 wolts e o lugar onde foi ligada era 220 wolts. Ele interpreta os diálogos, relembra a fala dos que estavam presentes. Num certo momento, fala em italiano, da forma em que foi dito, e logo traduz para mim. É dessa entrega que a performance exige do contador que emana a poesia, fazendo com que a emoção, o fascínio atinjam todos que participam do momento. Tanto quem conta como quem ouve faz parte dessa performance. Zumthor explica o seguinte sobre o papel do corpo na performance: 
é ele que eu sinto reagir, ao contato saboroso dos textos que amo; ele vibra em mim, uma presença que chega à opressão. $\mathrm{O}$ corpo é o peso sentido na experiência que faço dos textos. Meu corpo é a materialização daquilo que me é próprio, realidade vivida e que determina minha relação com o mundo. Dotado de uma significação incomparável, ele existe à imagem de meu ser: é ele que eu vivo, possuo e sou, para o melhor e para o pior. $(2007$, p. 23 )

Ao falar que nós nunca vamos passar por isso que ele conta, que só saberemos se tiver alguém contando mesmo, resume para mim a importância das narrativas orais, das contações de histórias. Ouvir o que os outros viveram, contar o que nós vivemos, é uma prática que não pode ser extinta. Para conhecermos o passado de nossa família, de nossas raízes, para sabermos como funcionavam as coisas antigamente, precisamos ouvir aqueles que viveram tudo isso, aqueles que têm o que contar. Para mim, o cinema é uma coisa extremamente comum, mas meu pai era jovem quando ele foi criado, e pode passar essa experiência para mim, contar a sua reação perante essa novidade. Isso eu nunca saberia de outra forma.

Com o aumento dos avanços tecnológicos, as culturas que não são focadas nas tecnologias e modernizações acabam perdendo espaço, e a tendência é direcionar-se cada vez mais para uma sociedade de consumo. Que lugar cabe, hoje em dia, às tradições culturais? Tudo está tão efêmero e frio, a intimidade vai se perdendo e dando lugar a algo praticamente robotizado. São tantas informações e principalmente tantos meios de comunicação e de muito fácil acesso, porém tudo parece mais distante. Resistem a tudo isso as formas de expressão corporal dinamizadas pela voz, pela poesia e pelas artes em geral.

Muitos estudam e perpetuam esse meio, e a expectativa é de que continuem aumentando os estudos e discussões sobre as poéticas da voz, dando espaço para aqueles que têm - e muito - o que contar.

\section{REFERÊNCIAS}


ALCOFORADO, Doralice F. Xavier. Oralidade e Literatura. In: LEITE, Fernando Eudes \& FERNANDES, Frederico. Oralidade e Literatura 3: outras veredas da voz (p 3 - 17). Londrina: Editora da Universidade Estadual de Londrina, 2007.

BENJAMIN, Walter. O Narrador. Considerações sobre a obra de Nikolai Leskov. In: Obras escolhidas: magia e técnica, arte e política. São Paulo: Editora Brasiliense, 1987.

COLOMBRES, Adolfo. Celebración del lenguaje. Buenos Aires: Ediciones Del Sol, 1997.

FERNANDES, Frederico. A voz e o sentido: poesia oral em sincronia. São Paulo: editora UNESP, 2007.

HARTMANN, Luciana. Performance e experiência nas narrativas orais da fronteira entre Argentina, Brasil e Uruguai. In: Horizontes Antropológicos: antropologia e performance. Porto Alegre, PPGAS/UFRGS, v. 11, n. 24, 2005.

BONDÍA, Jorge Larrosa. Notas sobre a experiência e o saber de Experiência. In revista eletrônica ANPEd, Jan/Fev/Mar/Abr 2002, No 19.

LEITE, Fernando Eudes \& FERNANDES, Frederico. Apresentação. In: Oralidade e Literatura 3: outras veredas da voz. Londrina: Editora da Universidade Estadual de Londrina, 2007.

ONG, Walter. Oralidade e cultura escrita: a tecnologização da palavra. São Paulo: Papirus Editora, 1988.

VICH, Víctor \& ZAVALLA, Virgínia. Oralidad y poder. Colombia: Grupo Editorial Norma, 2004

ZUMTHOR, Paul. Performance, recepção, leitura. São Paulo: Cosac Naify, 2007. Introdução à poesia oral. São Paulo: Editora Hucitec, 1997. 